\title{
AVALIAÇÃO SENSORIAL DE CHIPS DE BATATA DOCE ROXA E BRANCA E ENRIQUECIDA COM ACIDO ASCÓRBICO
}

\author{
A. A. C. PAGANI ${ }^{1}$; T. S. LEITE ${ }^{1}$; C. A.G. ${ }^{1}$; C. T. T. ${ }^{1}$; C.S. BERY ${ }^{2}$; G.F.SILVA ${ }^{2}$ \\ ${ }^{1}$ Universidade Federal de Sergipe, Departamento de Tecnologia de Alimentos \\ ${ }^{2}$ Universidade Federal de Sergipe, Núcleo de Graduação em Engenharia de Petróleo \\ *e-mail: alespagani@yahoo.com.br
}

\begin{abstract}
RESUMO
As raízes da batata doce, além dos carboidratos complexo de baixo índice glicêmico, é rica em fibras, ferro, vitamina $\mathrm{C}$ e potássio, além de apresentar alto teor de vitamina $\mathrm{E}$ e açucares, também são excelentes fontes de carotenóides, vitaminas do complexo B e cálcio desempenhando um importante papel na alimentação, sendo muito consumida por atletas. Um dos processos industriais que pode ser utilizado é a secagem ou desidratação para produção de chips de batata doce, com formulações diferenciadas para atribuir ao produto um aspecto sensorial aceitável ao consumidor. $\mathrm{O}$ presente trabalho tem como objetivo a produção de chips de batata doce roxa e branca, com a finalidade de agregar valor à matéria-prima, disponibilizando uma nova forma de comercialização do produto, como também avaliar a aceitabilidade sensorial. O teste de aceitação foi realizado por 50 avaliadores não treinados que avaliaram os atributos de aparência, cor, aroma e textura por meio de uma escala hedônica estruturada de nove pontos, como também o teste de aceitabilidade do produto. $\mathrm{O}$ teste de aceitação mostrou que os chips de batata doce roxa sem tratamento (CBRST) obteve $82 \%$ de aceitação sendo maior que os chips de batata doce branca com tratamento de ácido ascórbico (1\%) (CBBCT) com 73\% e a batata doce branca (CBBST) sem tratamento com 69\% de aceitabilidade. Conclui-se que os chips das duas variedades de batata doce, apresentaram uma boa aceitabilidade sensorial.
\end{abstract}

\section{INTRODUÇÃO}

A batata-doce (Ipomoea batatas (L.) Lam.) é a quarta hortaliça mais consumida no Brasil, muito popular e apreciada em todo o país (MELO et al., 2009). A maior parte de sua comercialização é realizada por meio de agentes intermediários que dá resultado numa menor margem de lucro para os agricultores e com isso desestimulando seu plantio (SILVA, 2010).

A batata doce participa do suprimento de calorias, vitaminas e minerais na alimentação humana. As raízes apresentam teor de carboidratos variando entre $25 \%$ a $30 \%$, dos quais $98 \%$ são facilmente digestíveis. Também são excelentes fontes de carotenóides, vitaminas do complexo B, potássio, ferro e cálcio. Suas raízes são tuberosas e variam de forma, tamanho e coloração, conforme a cultivar e o meio ambiente em que são produzidas (SILVA, 2010).

De acordo com Araújo (2014) o desenvolvimento de novos produtos é muito importante para indústria de alimentos, através da diversidade de inovações é possível a abertura de um leque de possibilidades que apresentam grande potencial de aceitação pelo mercado consumidor. Desta forma, a análise sensorial apresenta-se como ferramenta fundamental para avaliar a probabilidade do produto desenvolvido ser comercialmente aceito. Visando agregar valor ao produto e 
renda aos agricultores, objetivou-se a produção de chips de batata doce, tanto da batata roxa quanto da branca, avaliando a sua aceitabilidade sensorial.

\section{MATERIAL E MÉTODOS}

Este trabalho foi desenvolvido no Laboratório de tecnologia de Produtos de Origem Vegetal, no Laboratório de Análise de Alimentos Departamento de Tecnologia de Alimentos (DTA), Universidade Federal de Sergipe (UFS), na cidade de São Cristóvão, Sergipe, Brasil. Foram utilizadas duas variedades de batata doce (branca e roxa) que foram adquiridas no CEASA de Aracaju-SE.

\subsection{Processamento dos chips de batata-doce}

Inicialmente as batatas foram higienizadas, descascadas e fatiadas na forma de chips em um mini processador industrial. As amostras de batata doce branca foram divididas duas porções sendo que uma passou apenas pelo tratamento higienização (CBBST), e a outra porção passou pelo tratamento de imersão em ácido ascórbico a $1 \% 30 \mathrm{mim}$ (CBBAA); as batatas roxas permaneceram in natura sem tratamento (CBRST). Em seguida foi realizada a secagem a $63^{\circ} \mathrm{C}$ por um período de $2: 45 \mathrm{hs}$ (duas horas e quarenta e cinco minutos) em secador de bandeja em camada fina e após desidratadas foram armazenadas a temperatura ambiente $\left(25^{\circ} \mathrm{C}\right)$ e umidade relativa $78 \%$ (Figura 1, 2 e 3 ) para posteriores análises.

Figura 1 -Chips de batata doce branca sem tratamento (CBBST)

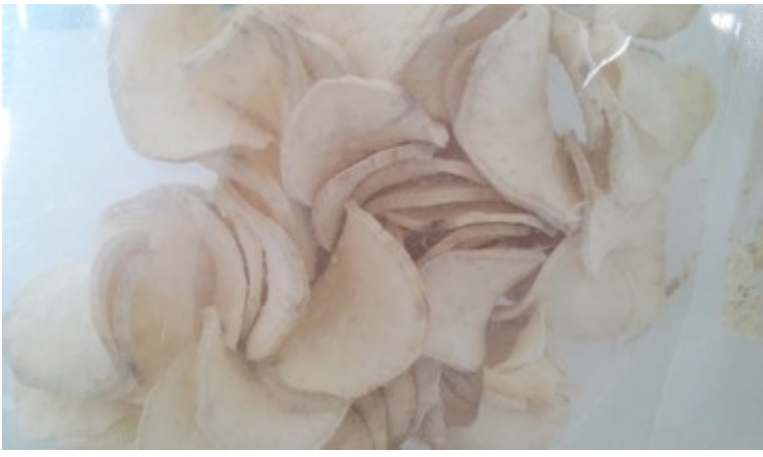

Fonte: Autor (2015)

Figura 2 -Chips de batata doce branca com ácido ascórbico a 1\% (CBBAA)

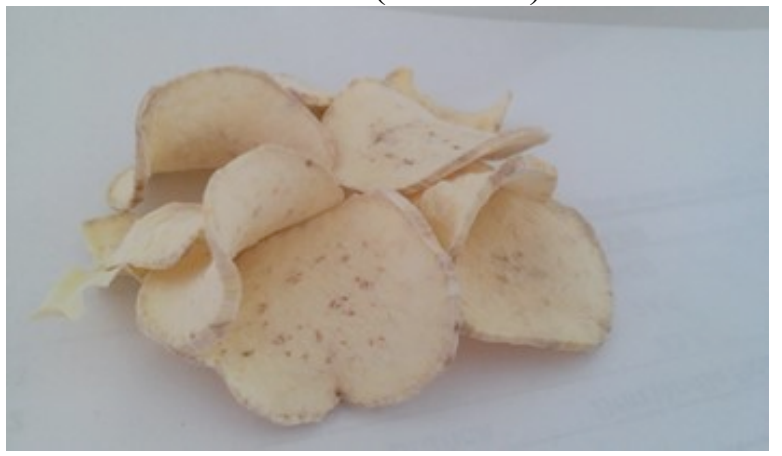

Fonte: Autor (2015)

Figura 3 -Chips de batata doce roxa sem tratamento (CBRST)

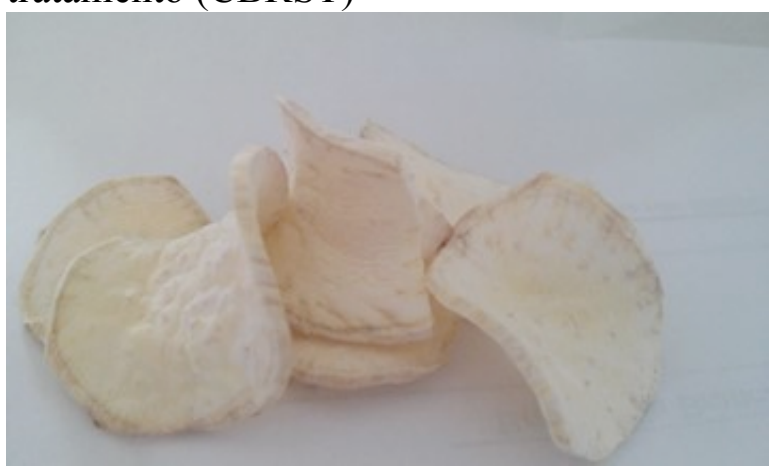

Fonte: Autor (2015)

\subsection{Rendimento}

O rendimento foi obtido por meio da pesagem dos chips de batata doce antes e após a secagem, calculando-se a razão entre a diferença multiplicada por 100 .

\subsection{Análises Físico químicas}


As amostras foram avaliadas quanto aos teores de umidade e cinzas. As análises físico-químicas foram realizadas em triplicata e segundo AOAC (1980).

\section{4 Ácido ascórbico}

Foi determinado de acordo com o método $\mathrm{n}^{\mathrm{o}} 43.065$ da AOAC (1984), modificado por Benassi \& Antunes (1988). No qual substitui a solução de extração de ácido metafosfórico por ácido oxálico.

\subsection{Carotenóides totais}

Os teores de carotenóides foram avaliados seguindo o método proposto por Lichtenthaler (1987) expressos em $\mu \mathrm{g} / \mathrm{g}$.

\section{6- Avaliação sensorial}

O teste de aceitação foi realizado por 50 avaliadores não treinados que avaliaram os atributos de aparência, sabor e textura por meio de uma escala hedônica estruturada de nove pontos, como também o teste de aceitabilidade do produto. As amostras de chips de batata doce foram padronizadas e os avaliadores realizaram o teste em cabines individuais, com condições controladas de temperatura e iluminação. Cada um foi servido com as amostras codificadas com três dígitos de números aleatórios.

Para a análise estatística dos dados utilizou-se a análise de variância (ANOVA) com comparação de médias pelo teste de Tukey a 5\% de significância por meio do programa estatístico Assistat versão 7.7 beta.

\section{RESULTADOS E DISCUSSÃO}

\subsection{Rendimento}

Os resultados para rendimento obtido em laboratório para os chips foram de $23,45 \%$ e $24,2 \%$ para as duas variedades de batata-doce branca e roxa, respectivamente.

\subsection{Caracterização físico química}

Os resultados dos parâmetros físico-químicos dos chips de batata-doce estão apresentados na Tabela 1. O teor de umidade dos chips de batata-doce, foram 4,5\% (CBBST), 5\% (CBBAA) e 5,5\% (CBRST), os quais estão de acordo com a Anvisa (2005) para produtos desidratados. As amostras CBBAA, mesmo após a secagem apresentou um teor de vitamina $\mathrm{C}$ significativo. Os chips das amostras CBRST apresentaram o maior teor de carotenoides totais com $61,79 \mu \mathrm{g} / \mathrm{g}$. Tomlins et al. (2012), avaliaram na África batata-doce e verificaram teores de carotenóides que variam de $0,4-72,5 \mu \mathrm{g} / \mathrm{g}$ b.u e $26,8-39,4 \%$ b.s.

Tabela 1 - Parâmetros físico-químicos dos chips de batata-doce

\begin{tabular}{cccc}
\hline Parâmetros & \multicolumn{3}{c}{ TRATAMENTO } \\
\hline & CBBST & CBBAA & CBRST \\
& & & \\
Umidade (\%) & $4,50 \pm 0,02$ & $5,01 \pm 1,15$ & $5,51 \pm 0,067$ \\
& & & \\
Cinzas (\%) & $2,91 \pm 0,07$ & $3,55 \pm 0,09$ & $3,01 \pm 0,02$ \\
& & & \\
Ácido & $10,86 \pm 11,4$ & $89,65 \pm 0,12$ & $13,16 \pm 1,16$ \\
ascórbico & & & \\
(mg/100g) & & &
\end{tabular}

\begin{tabular}{l}
$\begin{array}{l}\text { Carotenoides } \\
\text { totais }(\mu \mathrm{g} / \mathrm{g})\end{array} \quad 49,86 \pm 0,11 \quad 59,88 \pm 0,71 \quad 61,79 \pm 0,33$ \\
\hline Fonte: Autor $(2015)$
\end{tabular}

3.3 Teste de aparência, sabor e textura dos chips de batata doce roxa e branca 
Percebe-se pelos dados da Tabela 2 que os chips foram bem aceito, entretanto os chips de batata doce roxa em todos os parâmetros tiveram notas mais elevadas. Araújo (2014) em seu estudo com batata doce roxa frita na forma de "chips" foi a mais preferida entre os avaliadores, com 63,33\% das intensões quando comparada com as amostras na forma palito. Resultado semelhante também foi encontrado por Dias (2011), que avaliou batatas minimamente processadas fritas após diferentes dias de armazenamento apresentando médias entre 7 (gostei moderadamente) e 8 (gostei muito) nos atributos aparência, cor, sabor e textura no dia 0 de armazenamento sem película.

Tabela 2 - Dados dos parâmetros sensoriais dos chips de batata doce

\begin{tabular}{llll}
\hline & Aparência & Sabor & Textura \\
\hline CBBST & $8,3^{\mathrm{a}}$ & $7,8 \mathrm{a}$ & $7,7 \mathrm{a}$ \\
CBBAA & $7,5 \mathrm{~b}$ & $7,5 \mathrm{a}$ & $7,0 \mathrm{~b}$ \\
CBRST & $8,6 \mathrm{a}$ & $8,5 \mathrm{~b}$ & $8,2 \mathrm{c}$ \\
\hline
\end{tabular}

Letras iguais na mesma coluna não diferem estatisticamente pelo teste de Tukey a 5\% de significância.

Fonte: Autor (2015)

\subsection{Teste de Aceitabilidade Sensorial}

O teste de aceitação mostrou que os chips de batata doce roxa (CBRST) obteve $82 \%$ de aceitação sendo maior que os chips de batata doce branca com tratamento de ácido ascórbico (1\%) (CBBAA) com 73\% e a batata doce branca (CBBST) sem tratamento com $69 \%$ de aceitabilidade (Figura 2). Araújo (2014) em sua pesquisa com batata doce roxa frita no formato "chips" obteve uma boa aceitabilidade com $63,33 \%$ no teste de aceitabilidade.

Figura 2 - Dados do teste de aceitabilidade dos chips de batata doce roxa e branca.

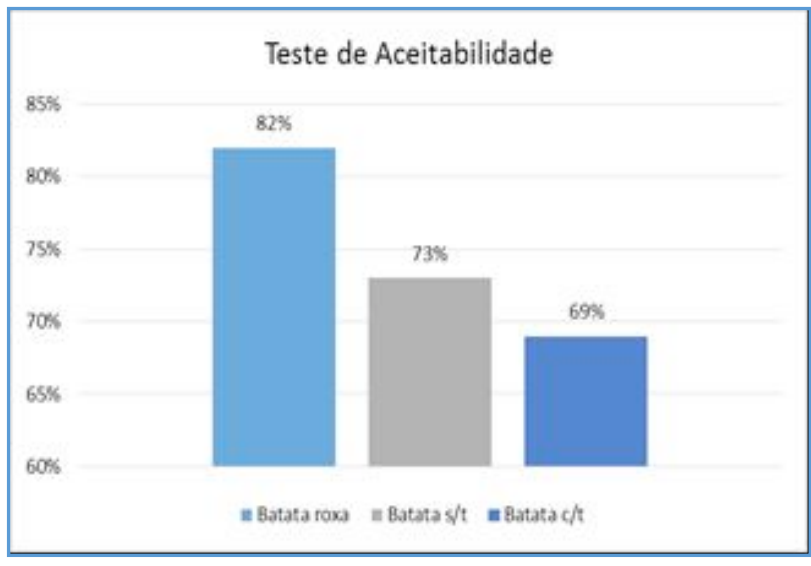

Fonte- Autor (2015)

\section{CONCLUSÃO}

Através da análise sensorial é possível afirmar a viabilidade de fabricação da batata doce na forma de "chips" devido ao valor nutricional agregado que atende aos teores determinados pela ANVISA e, sendo desta forma, uma inovação que apresenta grande potencial ao mercado alimentício.

\section{REFERENCIAS}

ARAÚJO, J. S. F; COSTA, J. S.; SILVA, G. M. S.; CAVALCANTI, M. T. Avaliação Sensorial De Batata-Doce Roxa "Chips" E Palito. Caderno Verde de Agroecologia e Desenvolvimento Sustentável - Dezembro, 2014. VOL. 4. No. 1

ASSOCIATION OF OFFICIAL ANALYTICAL CHEMISTS - AOAC. Official methods of analysis of the Association of Official Analytical Chemists. 14. ed. Washington, DC; 1141p., 1984.

BENASSI, M. T.; ANTUNES, A. J. A comparison of meta-phosphoric and oxalic acids as extractant solutions for the determination of vitamin $C$ in selected vegetables. Arq. Biol. Tech., 31(4): 507 1988. 
CARVALHO, M. P. M.; MOURA, L. L.; PAPE, G. Processo de obtenção de farinha de batata-doce. Pcsq. agropec. bras,, Brasilia, 16(4):551-556,juL/ago. 1981.

Lichtenthaler, H.K. Chlorophylls and carotenoids: pigments of photosynthetic biomembranes. Methods of Enzymology, v.148, p.350-382. 1987.

DIAS, P. D. B. Efeito da utilização de película e de diferentes formas de acondicionamento na conservação póscolheita e fritura de batatas minimamente processadas. 2011. 137p. Dissertação (Mestrado em Ciência e Tecnologia de Alimentos) - Escola Superior de Agricultura "Luíz Queiroz", Universidade de São Paulo, Piracicaba, 2011.

FIGUEIREDO, A. F. Armazenamento de rama, tipos de estacas, profundidade de plantio e análise do crescimento de plantas de batata-doce (Ipomea batatas L.). 1995. 127 f. (Tese doutorado) - Universidade Federal de Viçosa, Viçosa.

MELO, A. S., COSTA, B. C., BRITO, M. E. B., AGUIAR NETTO, A. O., VIÉGAS, P. R. A. Custo e rentabilidade na produção de batata-doce nos perímetros irrigados de Itabaiana, Sergipe. Pesquisa Agropecuária Tropical, v. 39, p.119-123. 2009.

SILVA, R. G. V. Caracterização físicoquimica de farinha de batata-doce para produtos de panificação. Universidade Estadual do Sudoeste da Bahia. Itapetinga, Bahia, 2010.

TOMLINS, K.; et al. Relationship among the carotenoid content, dry matter content and sensory attributes of sweet potato. Food Chemistry, v. 131, n.1, p. 14-21, 2012. 